\title{
The Johann Jacob Wepfer Award 2014 of the European Stroke Conference to Professors Stephen M. Davis and Geoffrey A. Donnan
}

This year's Wepfer Award for Excellence in Stroke Research is again shared by two giants in the field, as last year from the same country, but this time Australia is in the limelight. This year is, however, unique in that these two giants are also 'brothers in science', having worked closely together for the last 25 years. This formidable pair is largely honored for their collaborative work which has contributed so hugely to progress in understanding and treating stroke and this will be celebrated by generations of stroke physicians to come. Such a close collaboration by such talented individuals for such a long time is probably unique in the field of stroke, and possibly even in the field of neurology, except perhaps that of C. Miller Fisher and Raymond D. Adams at the Massachusetts General Hospital (MGH), Boston, Mass., USA, by no means a small pair. This year's Wepfer Award must serve as an example for young stroke scientists, as it demonstrates how hugely beneficial collaboration in science can be. Let us first survey their impressive titles, honors and distinctions.

Stephen M. Davis has been Professor of Translational Neuroscience at the University of Melbourne, Director of the Melbourne Brain Centre and of Neurology at the Royal Melbourne Hospital, and President of the World Stroke Organization since 2012. He is past president of the Australian and New Zealand Association of Neurologists and the Stroke Society of Australasia. He has received the 2011 William Feinberg Award from the American Stroke Association, the 2012 E. Graeme Robertson Award from the
Australian and New Zealand Association of Neurologists, the Bethlehem Griffiths Foundation Research Medal in 2011 and the 2012 Karolinska Award. He was the recipient of an Order of Australia Award in 2013. He is a consulting editor for Stroke and serves on editorial boards for Cerebrovascular Diseases, the Journal of Clinical Neuroscience, the International Journal of Stroke and the Journal of Neuroimaging. Steve Davis and Geoffrey A. Donnan co-founded Neurosciences Trials Australia, which incorporates neuroscience interest groups ranging from stroke to migraine, and provides coordination and support for commercial and investigator-driven clinical trials.

Geoff Donnan is currently Director of The Florey Institute of Neuroscience and Mental Health and Professor of Neurology, University of Melbourne, Austin Hospital in Australia. He has been involved in a number of international initiatives, including the establishment of the World Neurology Foundation and the World Stroke Foundation (Secretary). He has chaired the scientific committee or executive committees of a number of international meetings, including the 6th International Symposium on Thrombolysis and Acute Stroke (2000), World Stroke Congress (2000) and World Congress of Neurology (2005) and was co-chair of the Education Committee for the World Stroke Congress, Vienna (2008). He has served on many international editorial boards, including Stroke (Co-Section Editor), Cerebrovascular Diseases (Associate Editor) and Lancet Neurology. He founded and

\section{KARGER}

E-Mail karger@karger.com

www.karger.com/ced
(C) 2014 S. Karger AG, Basel

1015-9770/14/0381-0055\$39.50/0 
is currently Editor-in-Chief of the International Journal of Stroke. He is past president of the Stroke Society of Australasia, the Australian Association of Neurologists and the World Stroke Organization. He was the recipient of the American Stroke Association William Feinberg award for excellence in clinical stroke research in 2007. He was awarded the Bethlehem Griffiths Research Foundation Medal for his outstanding contribution to international stroke research in 2008, and in 2012 was appointed Officer in the Order of Australia in the Queen's Birthday Honors list for his distinguished service to neurology and his research contributions. He also received the World Stroke Organization's Leadership in Stroke Award and the Karolinska Institute's Award for Excellence in Stroke Research.

Geoff Donnan and Steve Davis' paths crossed very early in their education years and somehow ran in parallel until they crossed again in the USA, never to diverge again. They both read medicine at The University of Melbourne, although at the time did not know each other particularly well. They then both trained in neurology in Melbourne, although at different hospitals: Geoff Donnan at the Austin under Peter Bladin and Steve Davis at the Royal Melbourne under Peter Ebeling. They were both awarded Australian Association of Neurologists positions: Geoff Donnan in the basic science laboratory of Tachi Yanagihara at the Mayo Clinic in Rochester, Minn., USA, and Steve Davis at the National Hospital for Neurology and Neurosurgery, London, UK. In 1980, Steve Davis took up a fellowship at the Cerebral Blood Flow and PET Laboratory at the MGH under Bob Ackerman. This Laboratory had built one of the first PET scanners ever located within the hospital and hence was convenient for imaging acute stroke patients. After a year at the Mayo Clinic, Geoff Donnan took up the position at the MGH vacated by Steve Davis. When they had both returned to Melbourne, they decided to make collaborative work.

Before surveying the latter, let us look at their separate contributions in the early part of their careers.

During his 2-year fellowship at the MGH, Steve Davis trained in applying the ${ }^{133} \mathrm{Xe}$ inhalation cerebral blood flow technique and ${ }^{15} \mathrm{O}$-PET in acute stroke. He was awarded the MD degree based on this work [1]. After he returned to Australia as Senior Lecturer in Neurology at Melbourne University, his research focused on carotid disease, particularly new imaging approaches using dynamic CT, and in parallel he studied subarachnoid hemorrhage and cholinesterase inhibitors for Alzheimer's disease. He soon turned to acute stroke with the emphasis on two specific themes. The first was SPECT imaging using novel perfusion tracers, which he published a number of seminal papers on, notably regarding crossed cerebellar diaschisis and hyperperfusion, beautifully illustrating the important concept of 'nonnutritional perfusion' that distinguishes useless reperfusion of necrotic tissue from reperfusion of the still viable penumbra [2]. Secondly, very early on he got involved in pilot studies of thrombolysis in basilar occlusion, and subsequently he was Co-PrincipaI Investigator (co-PI) on the Australian Streptokinase Trial (ASK) with Geoff Donnan (see below). He was also co-PI on several neuroprotection trials, including the selfotel (ASSIST), gavestinel (GAIN) and NXY-059 trials (SAINT I and II), and the Recombinant Activated Factor VII for Acute Intracerebral Hemorrhage Trial.

In 1979, Geoff Donnan completed his neurology training in Australia and in one of his early papers he studied transient global amnesia where in 1980 he perhaps prophetically suggested that this clinical syndrome was related to hippocampal dysfunction. He also trained in electrophysiology, specifically on evoked potentials, which he applied to various clinical questions. But he soon made a decisive turn to stroke. He became involved in lacunar stroke and made important contributions in this area, for instance in 1982 regarding CT findings (this was the early days of CT and being able to see a lacunar infarct in a living patient was something amazing at the time!). He went on to describe in the same year the syndrome of stuttering deficits in capsular lacunes, which he coined 'capsular warning syndrome' [3]. For this and related work, he was awarded the MD degree. After returning from Boston, his early research grants were in the field of basic science of parkinsonism. His work focused on the dopamine system and the then popular MPTP model of Parkinson's disease. He published 5 papers as first author from this work - an early hint to his subsequent formidable productivity! In the early 1990s, he co-authored several important papers in the field of Parkinson's disease. While continuing his clinical research in parallel, he was among the first to describe the clinical syndrome of striatocapsular infarction and addressed the confusion that then surrounded the field of subcortical infarction by publishing with other famous colleagues a definitive classification and terminology in 1993, in the aftermath of an international workshop in Geneva, Switzerland, that he had organized and that hosted the world experts on this topic, including Miller Fisher who rarely if ever travelled at that time [4]. In the early 1990s, Geoff Donnan also developed a strong interest in the methodology of clinical trials and neuroepidemiology, and quickly published a string of papers on stroke and smoking, stroke and patent 
foramen ovale and aspirin therapy, but also on gliomas. For instance, he ran a study using CT which provided early evidence for the role of smoking as a risk factor, which was published in 1989 in the Lancet. He was involved in the early pilot trials on triptans in the treatment of migraine and started to actively publish in the field of acute stroke as early as 1987 . He soon became a pioneer and expert in thrombolysis for acute stroke, publishing a pilot study on intra-arterial therapy as early as 1993.

As already mentioned, both Steve Davis and, soon after him, Geoff Donnan were fellows at the Cerebral Blood Flow Laboratory at the MGH, which contributed to key advances on the viable brain in acute stroke [5]. There they both trained in the then novel - and technologically challenging - science of perfusion imaging of the brain as applied to stroke. Back in Australia, they quickly started a collaboration on SPECT in acute and subacute stroke and published numerous seminal reports that addressed the pathophysiology of acute ischemia. They were also the co-PIs of the ASK testing thrombolysis within $4 \mathrm{~h}$ of onset [6] and were both strongly involved in the ECASS II trial. They were among the pioneers of MR-based perfusion and diffusion imaging in acute stroke, publishing together many seminal papers on the PWI-DWI mismatch, its clinical correlates and pathophysiological significance, particularly as a representation of the penumbra [7]. They published important papers on power calculation for MR-based trials and were co-PIs of the EPITHET trial of intravenous t-PA versus placebo in the 3- to 6-hour time window, testing whether patients with PWI-DWI mismatch at delayed times benefitted more from thrombolysis than placebo-treated patients [8]. Although this study failed to show a positive outcome using the primary endpoint, it was positive on all other endpoints, and reanalysis of the data using state-of-the-art image processing showed strongly positive effects. This study, together with DEFUSE and DEFUSE 2, was the first to provide strong evidence that patients with the 'target mismatch' profile derive benefit from reperfusion therapy started beyond the currently licensed window, and these results have made perfusion imaging-based triage almost universal in current acute stroke trials. They also recently launched the EXTEND trials, which apply the findings from these studies to investigate the effects of intravenous t-PA or thrombectomy versus placebo $4.5-9 \mathrm{~h}$ after stroke onset in patients with the target mismatch profile. If positive, these trials will radically change acute stroke management by allowing a significant extension of the currently licensed therapeutic window. They then also participated in a seminal phase IIb trial showing that tenecteplase was more beneficial than intravenous t-PA within $4.5 \mathrm{~h}$ of stroke onset in patients with CT-defined target mismatch profile, demonstrating the feasibility of showing strongly significant effects in small but highly homogeneous samples. Both Geoff Donnan and Steve Davis have also, often together, participated in numerous key multicenter international trials on stroke prevention, either as members of the steering or safety committee or as co-PIs and recruiting centers, such as PROGRESS.

Another of their joint achievements was as (founding) Co-Editors of the 'Controversies' section of the journal Stroke from 2001 to 2010, by selecting every other month a particularly relevant, hot topic in stroke management and providing a rational synthesis of two radically opposed views - always both a highly enjoyable read and a useful take-home message.

Together with David Howells and Malcolm Macleod, Geoff Donnan was also involved in basic stroke research and adapted the meta-analysis technique to assess therapies in animal stroke models. This led to several systematic reviews [9] that brought to light major biases in the way in which preclinical neuroprotection stroke studies are reported, and indeed sometimes carried out, misleading one into believing that a given agent provided effective neuroprotection when in fact the unpublished data and abstracts indicated neutral or even detrimental effects. In retrospect, this work provided potential explanations for the apparent discrepancies between expected and actual clinical effects of neuroprotectants, particularly with respect to highly publicized failed phase III trials such as SAINT I and II. This work was also seminal to the recently enforced policies regarding good laboratory practice for preclinical stroke trials and how to publish them. Geoff Donnan also pioneered in the use of hypoxia PET tracers in acute stroke, showing in a string of elegant papers in both rats and in clinical papers the potential of ${ }^{18} \mathrm{~F}$-fluoromisonidazole to depict the penumbra. Finally, in collaboration with Leanne Carey, he was also involved in a series of articles using fMRI to investigate the plastic processes underlying stroke recovery.

Together with other colleagues, Geoff Donnan and Steve Davis also published the only book devoted to the ischemic penumbra ever marketed [10], and two highly cited review articles on stroke in the Lancet in 2008 [11] and on secondary prevention after ischemic stroke or transient ischemic attack in the New England Journal of Medicine in 2012 [12]. Their authoritative as well as provocative Lancet Neurology review articles on the penumbra and how to design stroke trials using penumbra imaging $[13,14]$ are also landmarks in the field. 
Geoff Donnan and Steve Davis have supervised nearly $50 \mathrm{PhD} / \mathrm{MD}$ students, several in co-supervision, and nurtured a bunch of outstanding stroke researchers, including Alison Baird, Romesh Markus, Stephen Read, Alan Barber, Chris Levi, Mark Parsons, Thanh Phan, Neil Spratt, Bruce Campbell, Henri Ma and Soren Christensen, who have all engaged in successful academic careers. In doing so, Geoff Donnan and Steve Davis have put Australia at the forefront of stroke research internationally, not only Melbourne but their country at large, where their former students have set up flourishing stroke departments with whom they closely collaborate through a highly efficient research and trial network.
Steve Davis and Geoff Donnan have each co-authored over 380 peer-reviewed papers, 130 of which have appeared in the journal Stroke. Even more amazingly, they have co-authored 252 papers - a model of fruitful collaboration!

Finally, and of particular relevance to the Wepfer Prize, they both, despite the very long and tiring journey from Melbourne, have attended the European Stroke Conference every year since its inception, each having given at least one talk each time - often two or three whose clarity and insight we have always enormously enjoyed.

Jean-Claude Baron, MD, ScD, FMedSci INSERM U894, Université Paris Descartes Sorbonne Paris Cité, Paris, France, and Emeritus Professor of Stroke Medicine, University of Cambridge, UK

\section{References}

1 Davis SM, Ackerman RH, Correia JA, Alpert NM, Chang J, Buonanno F, Kelley RE, Rosner B, Taveras JM: Cerebral blood flow and cerebrovascular $\mathrm{CO}_{2}$ reactivity in stroke-age normal controls. Neurology 1983;33:391-399.

2 Infeld B, Davis SM, Lichtenstein M, Mitchell PJ, Hopper JL: Crossed cerebellar diaschisis and brain recovery after stroke. Stroke 1995; 26:90-95.

3 Donnan GA, Tress BM, Bladin PF: A prospective study of lacunar infarction using computerized tomography. Neurology 1982;32:4956.

4 Donnan GA, Norrving B, Bamford JM, Bogousslavsky J (eds): Lacunar and Other Subcortical Infarctions. Oxford, Oxford University Press, 1995.

5 Baron JC: Stroke research in the modern era: images versus dogmas. Cerebrovasc Dis 2005; 20:154-163.
6 Donnan GA, Davis SM, Chambers BR, Gates PC, Hankey GJ, McNeil JJ, Rosen D, StewartWynne EG, Tuck RR: Streptokinase for acute ischemic stroke with relationship to time of administration: Australian Streptokinase (ASK) trial study group. JAMA 1996;276: 961-966.

7 Barber PA, Darby DG, Desmond PM, Yang Q, Gerraty RP, Jolley D, Donnan GA, Tress BM, Davis SM: Prediction of stroke outcome with echoplanar perfusion- and diffusionweighted MRI. Neurology 1998;51:418-426.

-8 Davis SM, Donnan GA, Parsons MW, Levi C, Butcher KS, Peeters A, Barber PA, Bladin C, De Silva DA, Byrnes G, Chalk JB, Fink JN, Kimber TE, Schultz D, Hand PJ, Frayne J, Hankey G, Muir K, Gerraty R, Tress BM, Desmond PM; EPITHET investigators: Effects of alteplase beyond $3 \mathrm{~h}$ after stroke in the Echoplanar Imaging Thrombolytic Evaluation Trial (EPITHET): a placebo-controlled randomised trial. Lancet Neurol 2008;7:299-309. $\checkmark 9$ O'Collins VE, Macleod MR, Donnan GA Horky LL, van der Worp BH, Howells DW: 1,026 experimental treatments in acute stroke. Ann Neurol 2006;59:467-477.

10 Donnan GA, Baron IC, Davis SM, Sharp F (eds): The Ischemic Penumbra. London, Informa Healthcare, 2007.

11 Donnan GA, Fisher M, Macleod M, Davis SM: Stroke. Lancet 2008;371:1612-1623.

12 Davis SM, Donnan GA: Clinical practice. Secondary prevention after ischemic stroke or transient ischemic attack. N Engl J Med 2012; 366:1914-1922.

13 Donnan GA, Davis SM: Neuroimaging, the ischaemic penumbra, and selection of patients for acute stroke therapy. Lancet Neurol 2002;1:417-425.

14 Donnan GA, Baron JC, Ma H, Davis SM: Penumbral selection of patients for trials of acute stroke therapy. Lancet Neurol 2009;8:261269 